FACTA UNIVERSITATIS

Series: Economics and Organization Vol. 18, No 5, 2021, pp. 407 - 420

https://doi.org/10.22190/FUEO210718029R

Original Scientific Paper

\title{
NEW METHODOLOGY TO STUDY CONTAGION BETWEEN WESTERN AND EMERGING EUROPE: A SWITCHING COPULA APPROACH
}

\author{
UDC 336.7
}

\section{Deyan Radev}

Sofia University "St. Kliment Ohridski",

Faculty of Economics and Business Administration, Sofia, Bulgaria

ORCID iD: Deyan Radev (i) https://orcid.org/0000-0002-0445-0397

\begin{abstract}
This paper adapts and extends switching copula models to investigate whether financial contagion occurred between Western stock markets and their Central and Eastern European counterparts during the Global Financial Crisis. Our methodology focuses on tail dependence as a direct measure of codependence in crisis times and we apply it to two bespoke indices that cover the biggest Central and Eastern European stock markets. We find an overall increase in dependence between Western Europe and the transition region during the Great Recession. However, adding the Turkish stock market to our CEE regional indices reduces the duration of the impact of the crisis. These results suggest that the transition economies remain a valuable diversification source during periods of crisis.
\end{abstract}

Key words: Contagion, International financial markets, Financial integration

JEL Classification: C32, F36, G15

\section{INTRODUCTION}

In the two decades prior to 2008, the transition region of Central and Eastern Europe (CEE) saw a steady economic growth due to the financial integration with Western Europe (Friedrich et al. 2013; Haselmann et al. 2009). However, the sharp decline of the stock markets of these countries during the Global Recession following the Lehman Brothers' collapse raised the question whether in addition to their superior returns in economic

Received July 18, 2021 / Revised November 21, 2021 / Accepted November 23, 2021

Corresponding author: Deyan Radev

Sofia University "St. Kliment Ohridski", Faculty of Economics and Business Administration, 125 Tsarigradsko

Shose Blvd., bl.3, 1113 Sofia, Bulgaria |E-mail: d.radev@feb.uni-sofia.bg

() 2021 by University of Niš, Serbia | Creative Commons Licence: CC BY-NC-ND 
upturns, they are a viable source of diversification in times of a turmoil. Therefore, the current paper investigates whether the financial markets in the CEE region became more interdependent with Western European (WE) markets during the crisis, which may cast doubt on the region's diversification potential.

We focus on the period from the beginning of 2007 to the beginning of 2010 and examine the stock markets of nine transition economies: Bulgaria, Croatia, Hungary, the Czech Republic, Estonia, Poland, Romania, Slovenia and Turkey, and one general Western European index, the Stoxx600. In our approach, we use an increase in the volatility in the Western European index as a potential trigger of financial contagion from WE to CEE.

Our methodology derives from the latest advancements in the literature on measuring financial contagion. In the last two decades, the discussion on contagion departed from the assumption of linearity, imposed by the definition of the Pearson correlation coefficient, and recognized the importance of tail events in gathering a finer grasp of the stock market fluctuations. This is intuitive, since a crisis is a tail event itself. Thus, extreme value theory and Markov switching models are becoming increasingly important in analyzing the phenomenon of contagion (see Longin \& Solnik 2001; and Hartmann et al. 2004, for the former approach, and Ramchard \& Susmel 1998; Ang \& Bekaert 2002; and Rodriguez 2007, for the latter).

When we consider dependence, a natural concept that comes to mind is the copula, that is, the pure dependence structure between individual markets. Therefore, to gauge financial contagion, we apply switching mixture copula models that capture the influence of different variance regimes, following the approach of Rodriguez (2007). Using this methodology, Rodriguez (2007) manages to identify not only differences in the level (the magnitude of the copula parameters), but also in the structure (the specific proportion of each copula in the copula mixture) of dependence between periods of low and high volatility. The most important benefit of the copula approach is that it provides direct estimates of tail dependence, i.e., the probability that two markets are simultaneously in extreme good or bad states. This concept allows us to test our predictions with regard to the behaviour of stock markets during crisis episodes.

To exemplify the usefulness of our approach, we examine the dependence patterns between WE and the overall CEE region. To this end, we construct a Central and Eastern European Index (CEEI) as a weighted average of the stock market indices of the nine transition economies in our sample. This should help us to distinguish any asymmetric responses at the regional level.

Our results show the following: First, we generally confirm the existence of contagion of the type proposed by Forbes \& Rigobon (2002) in a broad sense - the regional dependence does increase at the time of the peaks of the crisis in the Western markets. As far as the second hypothesis is concerned - whether markets tend to comove to a higher extent during downturns than during upturns, at the regional level, we witness a balanced dependence structure, with a fairly symmetric level of dependence in both tails.

We have several contributions to the existing financial contagion literature. First, we are among the few to apply copula theory to study the contagion between Central and Eastern Europe and Western Europe during the subprime crisis, with an explicit focus on tail dependence. Second, the use of Markov Chain models like SWARCH allows us to endogenize crisis periods, instead of setting arbitrarily fixed dates like previous studies. Third, we extend the switching copula methodology to allow us to make not only qualitative, but also quantitative statements about the form of dependence, and thus - to gain more intuition about the level of interdependence between WE and CEE markets during the subprime crisis. 
This paper is organized as follows: Section 2 places the current work within the existing literature regarding contagion and the dependence between the financial markets of WE and CEE. In section 3, we introduce our switching copula methodology, outline its properties and provide guidelines on how our results should be interpreted. Section 4 discusses our dataset and empirical strategy, while section 5 presents our empirical results. Section 6 summarizes our results, and discusses possible policy implications and venues for further research.

\section{LITERATURE REVIEW}

The debate on the issue of contagion in stock markets gained momentum after the 'Peso' and Russian crises in the 90s. This notion is usually discussed in the context of the findings of Longin \& Solnik (2001), who observe a rise in dependence in bear, but not in bull markets. Forbes \& Rigobon (2002) define financial contagion as a substantial rise in market interlinkages after an adverse event in a particular market or region. While the early empirical evidence confirms the rise of correlation during stock market crashes (see Bertero \& Mayer 1990; and King \& Wadhwani 1990, for the 'Crash of 1987'), Boyer et al. (1999) and Forbes \& Rigobon (2002) did not find structural breaks in correlation once they accounted for conditional heteroskedasticity.

In the early research activity with regard to the stock markets of the transition economies, authors usually prefer to use vector autoregressive models to detect any cointegration relationships between CEE and WE and do not explicitly concentrate on extreme-event comovement and contagion during crisis periods (see, e.g., Horváth \& Petrovski 2012, Egert \& Kočenda 2011; Tilfani et al. 2019; and Beck \& Stanek 2019).

More recently, researchers have started to apply VAR methods to study contagion in CEE more generally and financial contagion in particular. Baruník \& Vácha (2013) use wavelet theory to address some deficiencies in standard VAR methods applied to time series and find that contagion within the CEE region, measured by conditional correlation, has dropped during the Global financial crisis. Not focusing on any specific crisis period, Baele et al. (2015) document significant heterogeneity in stock markets development in the region since 1990 and that smaller and less liquid markets offer high diversification benefits. The authors also find significant premiums in investing in low-volatility markets. Horváth et al. (2018) apply VAR models and quantile regressions to measure financial contagion as defined by Forbes and Rigobon (2002) and find evidence that general dependence between WE and CEE stock markets increases during crises. However, using their methodology, they are not able to generate exact estimates of tail dependence and set the crisis period exogenously, in contrast to our Markov-Chains-based approach that defines crisis periods endogenously. Using DCC-GARCH model, Csiki \& Kiss (2018) find evidence for increased correlation between Poland, Hungary and the Czech Republic with the USA and Germany. Moagăr-Poladian et al. (2019), Niţoi \& Pochea (2019) and Grabowski (2019) find similar results using a GARCH-MIDAS approach.

Overall, these studies suffer from the shortcoming of the earlier literature: They focus on general linear correlation (albeit sometimes in the tails), rather than on tail dependence (which is a probability concept), do not assess how symmetric the market response is in good and bad times and in both tails of the distribution, and define the crisis periods exogenously.

To our knowledge, only a couple of recent studies, Reboredo et al. (2015) and Mohti et al. (2018), apply copulas to study financial contagion in the CEE region and are therefore the most closely related articles to our paper. Reboredo et al. (2015) use dynamic Student-t, 
Gaussian, Clayton and Gumbel copulas to find the best fit to the data and document that dependence among CEE markets increases during crises and that it is mostly symmetric within the geographic region. In contrast to that study, we focus on tail dependence between $\mathrm{CEE}$ and $W E$ and find that the dependence is symmetric at the region-region level. Mohti et al. (2018) analyze financial contagion between the USA and a number of emerging markets in Asia, South America and CEE and find an increase in dependence during the Global financial crisis for CEE. These two studies suffer from the pitfalls of most other studies that apply copulas to study financial contagion: First, they horse-race a large number of copulas with different characteristics and properties and look for the one with the best fit with the data. This leads to interpreting the parameters of the 'winning' copula, which do not always represent tail dependence directly. Instead, in our case, we use a flexible mixture copula with parameters that exactly measure lower and upper tail dependence. Second, they set the crises periods exogenously and arbitrarily. Our SWARCH approach allows us to endogenously identify periods with high volatility in stock markets. Both these features of our approach yield superior modelling and intuitive interpretation of our results.

In a more general context, in terms of sophistication of the copula approach, our study shares common features with the approach of Johansson (2011) (aside from the obvious similarities with Rodriguez 2007 that we compared with in the introduction). Johansson (2011) models the asymmetry in the volatility of East Asian and WE stock markets using an EGARCH model and estimates the upper and lower tail dependence using a symmetrized Joe-Clayton (SJC) copula. The author documents increased volatility in the beginning of the crisis and the period around the bankruptcy of Lehman Brothers, but assigns the starting dates and the lengths of those periods exogenously, while we endogenize them. A second differentiation is that the copula function that Johansson (2011) uses is time-varying, which allows the author to capture the time path of the tail dependence, while we assume a constant dependence structure that may be different in each of the volatility states that we model. The implementation of a time-varying approach has it pitfalls, as the results are sensitive to the choice of lags and length of the rolling estimation window in the time-variation-forcing mechanism. Also, although the author documents shifts in tail dependence in Western Europe and Asia during periods of high volatility, he does not analyze different volatility regimes that might lead to a structural break in the tail dependence. Fourth, the author does not differentiate between lower and upper tail dependence, while this differentiation is crucial for the current analysis, since it allows us to analyze any potential asymmetric dependencies between the WE and CEE regions. Finally, while Johansson (2011) examines the within-regional tail dependence of the WE and Asian stock markets, we focus on cross-regional tail dependence, since our aim is to investigate contagion patterns between WE and CEE regions.

\section{METHODOLOGY}

Our procedure entails using publicly available data to model the marginal distributions of the investigated markets as a first step. We start by creating a Central and Eastern European Index (CEEI) to analyze the behavior of the region as a whole. Following Hamilton and Susmel (1994) and Rodriguez (2007), we use a Switching ARCH (SWARCH) model to describe the marginal behaviour of each stock market.

As a second step, we use the results from the SWARCH estimation to model the joint behaviour between the CEE countries and Western Europe using copula models. We extend the approach of Rodriguez (2007) by introducing a switching parameter version of 
a specific copula, the symmetrized Joe-Clayton copula, developed by Patton (2006). Using a single copula, we avoid the non-nestedness of the structures derived from general copula mixtures, which allows us to compare the results across different markets. The symmetrized Joe-Clayton copula is flexible enough to capture differences in both the level and the structure of dependence. Most importantly, this copula's parameters are consistent tail dependence estimates, that is, estimates of the probability of the markets to simultaneously be in extreme good or bad states.

\subsection{Switching ARCH Model (Hamilton and Susmel 1994)}

We estimate the characteristics of the marginal distributions of the time series using an $\operatorname{AR}(\mathrm{p})-\mathrm{SWARCH}(\mathrm{K}, \mathrm{q})$ model (Hamilton and Susmel 1994). To this end, we assume that the conditional mean follows a regime-dependent process:

$$
y_{t}=\mu_{s_{t}}+\tilde{y}_{t},
$$

with $\mu_{s_{t}}$ being the mean in the states $s=1,2, \ldots, K$ at the respective time $t . \tilde{y}_{t}$ is governed

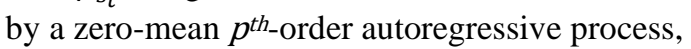

$$
\tilde{y}_{t}=\phi_{1} \tilde{y}_{t-1}+\phi_{2} \tilde{y}_{t-2}+\cdots+\phi_{p} \tilde{y}_{t-p}+u_{t} .
$$

Furthermore, we model the error term as:

$$
u_{t}=\sqrt{g_{s_{t}}} \cdot \tilde{u}_{t}
$$

with $\tilde{u}_{t}$ following an $\mathrm{ARCH}(\mathrm{q})$ process:

$$
\tilde{u}_{t}=h_{t} \cdot v_{t}
$$

where $v_{t}$ is an i.i.d. sequence with a mean equal to zero and a variance equal to one. Also, $h_{t}$ follows

$$
h_{t}^{2}=a_{0}+a_{1} \tilde{u}_{t-1}^{2}+a_{2} \tilde{u}_{t-2}^{2}+\cdots+a_{q} \tilde{u}_{t-q}^{2} .
$$

The changes in the regimes are captured via changes in the level of the variance process in each state (represented by $g_{s_{t}}$ ).

A Markov chain of the following form describes the latent variable:

$$
P=\left[\begin{array}{cccc}
p_{11} & p_{21} & \cdots & p_{k 1} \\
p_{12} & p_{22} & \cdots & p_{k 2} \\
\cdots & \cdots & \cdots & \cdots \\
p_{1 k} & p_{2 k} & \cdots & p_{k k}
\end{array}\right],
$$

with Pro b $\left(s_{t}=j \mid s_{t-1}=i\right)=p_{i j}, i, j=1,2, \ldots, K$, and where the sum of every column is 1 .

We choose to model the stock market returns using an $\operatorname{AR}(1)-\operatorname{SWARCH}(2,1)$ model, which yields parsimonious results and secures convergence. The residuals $v_{t}$ are Student tdistributed.

\subsection{Copulas and Tail Dependence}

Using copula theory (Sklar 1954; Cherubini et al. 2004), we define tail dependence as

$$
\tau^{U}=\lim _{q \rightarrow 1} \operatorname{Pr}\left[U_{1}>q \mid U_{2}>q\right]=\lim _{q \rightarrow 1}(1-2 q-C(q, q)) /(1-q),
$$


and

$$
\tau^{L}=\lim _{q \rightarrow 0} P r\left[U_{1}<q \mid U_{2}<q\right]=\lim _{q \rightarrow 0} C(q, q) / q,
$$

with $\tau^{U}$ and $\tau^{L}$ being estimates of, respectively, upper and lower tail dependence. $U_{1}$ and $U_{2}$ are uniform integral transforms of processes $X_{t}$ and $Y_{t}, U_{1}=F_{1}\left(X_{t}\right)$ and $U_{2}=F_{2}\left(Y_{t}\right)$, and $X_{t}=F_{1}^{-1}\left(U_{1}\right)$ and $Y_{t}=F_{2}^{-1}\left(U_{2}\right) ; q$ is the quantile of an univariate distribution and $C(q, q)$ is a bivariate copula (Sklar 1954).

The dependence structure can be estimated using many different copulas, which are then usually ranked with the Akaike Information Criterion (AIC) to find the best fit. This widely spread approach is problematic because of the non-nestedness of the different copula families. Therefore, the tail dependence estimates are not comparable across copulas. We solve this problem by using a flexible mixed copula, the symmetrized JoeClayton copula (SJC copula; Patton 2006). The SJC copula can capture any type of asymmetry in the tail dependence between markets, including the case of independence. Another valuable feature is that, in contrast to most other copulas, where a transformation of the copula parameters is needed to arrive at tail dependence estimate, the parameters of the SJC copula themselves are consistent estimates of $\tau^{U}$ and $\tau^{L}$. Our innovation to the approach is that the parameters change with the state of volatility between markets.

The standard Joe-Clayton copula (JC copula; Patton 2006) takes the following form:

$C_{J C}\left(u, v \mid \tau^{U}, \tau^{L}\right)=1-\left(1-\left\{\left[1-(1-u)^{\kappa}\right]^{-\gamma}+\left[1-(1-v)^{\kappa}\right]^{-\gamma}-1\right\}^{-1 / \gamma}\right)^{1 / \kappa}$

where $\kappa=1 / \log _{2}\left(2-\tau^{U}\right)$, and $\gamma=-1 / \log _{2}\left(\tau^{L}\right)$.

The standard JC copula possesses intrinsic asymmetry even with equal upper and lower tail dependence, hence Patton (2006) introduces the SJC as:

$$
\begin{aligned}
C_{S J C}\left(u, v \mid \tau^{U}, \tau^{L}\right) & =0.5\left(C_{J C}\left(u, v \mid \tau^{U}, \tau^{L}\right)\right) \\
& +0.5\left(C_{J C}\left(1-u, 1-v \mid \tau^{U}, \tau^{L}\right)+u+v-1\right),
\end{aligned}
$$

with $C_{J C}\left(1-u, 1-v \mid \tau^{U}, \tau^{L}\right)+u+v-1$ being the Survival JC copula.

\subsection{Switching Copulas}

Next, we introduce the mechanism of work of the switching copula for the bivariate case. Following Ramchard and Susmel (1998) and Rodriguez (2007), we assume that one of the markets, the WE market, is the source of change in volatility and tail dependence. In a two-market setting, there are four states in the Markov Switching Model. As an example, the states of volatility for WE and Poland at time $t$ are as follows:

$s_{t}=1$ : Poland - Low Variance; Western Europe - Low Variance.

$s_{t}=2$ : Poland - High Variance; Western Europe - Low Variance.

$s_{t}=3$ : Poland - Low Variance; Western Europe - High Variance.

$s_{t}=4$ : Poland - High Variance; Western Europe. - High Variance.

The elements of the transition matrix $P$ are of the following form: Pro b $\left(s_{t}=j \mid s_{t-1}=\right.$ $i)=p_{i j}$. According to Hamilton and Gang (1996), due to its flexibility, such structure can accommodate different relationships between the univariate variance states. In case that, for instance, there is independence between Poland and WE, each bivariate transitional probability, for instance $p_{24}$, could be constructed as the product of the respective univariate probabilities. That is, $p_{24}=p_{12}^{W E} \cdot p_{22}^{P L}$. 
Previous research has shown that the Great recession affected CEE markets through their links with WE (see, for instance, Dabrowski 2009 and Gardo and Martin 2010). Therefore, we set the copula parameters to change only when there is a switch from low to high volatility in the WE market. Hence, tail dependence in states 1 and 2, and in states 3 and 4 , respectively.

Rodriguez (2007) explains that all parameters in the switching model, including these of the SJC copula change jointly when there is a switch in the states of volatility. Therefore, we cannot separate the estimation of the marginal distribution and the copula in two steps, as usually done in previous research.

The likelihood function then takes the following form:

$$
\begin{aligned}
q_{t}\left(x_{t}, y_{t} \mid I_{t-1} ; \Theta\right)= & \sum_{s_{t}} \sum_{s_{t-1}} f_{t}\left(x_{t} \mid s_{t}, s_{t-1}, I_{t-1} ; \Theta\right) \times g_{t}\left(y_{t} \mid s_{t}, s_{t-1}, I_{t-1} ; \Theta\right) \\
& \times c^{S J C}\left(u_{t}, v_{t} \mid s_{t}, s_{t-1}, I_{t-1} ; \Theta\right) \times P\left(s_{t}, s_{t-1} \mid I_{t-1} ; \Theta\right),
\end{aligned}
$$

with $P\left(s_{t}, s_{t-1} \mid I_{t-1} ; \Theta\right)$ being the probability of each state at time $t$ given the information set up to $t-1 ; c^{S J C}, f$ and $g$ are, respectively, the densities of the copula and the marginals. $\Theta$ represents the set of parameters, and $u_{t}=F_{x}\left(x_{t} \mid s_{t}, s_{t-1}, I_{t-1} ; \Theta\right)$ and $v_{t}=$ $F_{y}\left(y_{t} \mid s_{t}, s_{t-1}, I_{t-1} ; \Theta\right)$ are the univariate conditional cumulative distribution functions. Then, the maximum likelihood function is represented by the following expression:

$$
L(\Theta)=\sum_{t=1}^{T} \log \left[q\left(x_{t}, y_{t} \mid I_{t-1}, \Theta\right)\right]
$$

In our exposition, we prefer to report the smoothed probabilities $P\left(s_{t} \mid I_{T} ; \Theta\right)$, instead of the filter probability $P\left(s_{t}, s_{t-1} \mid I_{t-1} ; \Theta\right)$. The smoothed probabilities take into account the information set of the complete sample. For the univariate series, there are two probabilities - for low and high volatility state, respectively, and for the bivariate case, we arrive at four series for the smoothed probabilities.

\section{DATA}

\subsection{Country and Regional Data}

Our dataset consists of ten stock price indices, downloaded from Datastream. The sample period extends from 03.01.2007 to 09.02.2010. We consider 9 CEE markets, which, ordered alphabetically, are: Bulgaria, Croatia, the Czech Republic, Estonia, Hungary, Poland, Romania, Slovenia and Turkey. The dynamics of WE markets is proxied by Stoxx600. Every data series consists of 810 observations at a daily frequency.

To arrive at tail dependence at the regional level, we introduce 2 variants of our CEE index (CEEI): CEEI includes the member countries of the European Union at the time of the Great Recession, while CEEI2 adds Croatia and Turkey.

\subsection{Descriptive Statistics}

In Table 1, we show the market capitalizations of the CEE countries in our analysis, as well as the weights of each market in the respective CEEI indices. The captured regional market size increases from $€ 260$ Billion in CEEI, to $€ 405$ Billion in CEEI2. In Table 2, we show additional distributional descriptive statistics of the daily logarithmic returns of both indices. For both indices, we observe average returns below zero, left skewness, and, overall, the normality of the series is rejected (see the Jarque-Bera test statistic). These 
observations confirm the fat tails of both series and provide support for our choice to use Student t-distribution for the SWARCH model.

Table 1 summarizes the market capitalizations (row "M. Cap.", in millions of Euro) of the stock markets of the CEE countries in our sample in the end of 2006. Also listed are the weights of each country in the respective CEEI and CEEI2 index (rows "Weights CEEI" and "Weights CEEI2").

Table 1 Central and Eastern European Indices: market capitalizations and weights

\begin{tabular}{lcccccc}
\hline Country & Bulgaria & $\begin{array}{c}\text { Czech } \\
\text { Republic }\end{array}$ & Estonia & Hungary & Poland & Romania \\
\hline Market Cap & 14802 & 57835 & 9797 & 31689 & 112831 & 21527 \\
Weights CEEI & 0.0569 & 0.2224 & 0.0377 & 0.1219 & 0.4340 & 0.0828 \\
Weights CEEI2 & 0.0365 & 0.1427 & 0.0242 & 0.0782 & 0.2785 & 0.0531 \\
\hline \hline Country & Slovenia & Croatia & Turkey & TOTAL: & \\
\hline Market Cap & 11514 & 22006 & 123163 & M. Cap. & Weights \\
Weights CEEI & 0.0443 & & & 259994.3423 & 1.0000 \\
Weights CEEI2 & 0.0284 & 0.0543 & 0.3040 & 405163.8072 & & 1.0000 \\
\hline
\end{tabular}

Table 2 presents descriptive statistics for the CEEI indices. CEEI includes Bulgaria, Czech Republic, Estonia, Hungary, Poland, Romania and Slovenia. CEEI2 adds Croatia and Turkey. Time period: 03.01.2007 to 09.02.2010.

Table 2 Descriptive statistics: Central and Eastern European Indices

\begin{tabular}{lcc}
\hline Index & CEEI & CEEI2 \\
\hline Mean & -0.0451 & -0.0162 \\
St. Dev. & 1.5304 & 1.5667 \\
Min & -9.3839 & -8.9880 \\
Max & 7.3266 & 8.7151 \\
Skewness & -0.4016 & -0.2666 \\
Kurtosis & 4.7169 & 4.1675 \\
Jarque-Bera & 771.7342 & 595.0321 \\
Observations & 809 & 809 \\
\hline
\end{tabular}

\section{EMPIRICAL RESULTS}

\subsection{Univariate Results}

In Table 3, we present the results for the marginals estimation for CEEI and CEEI2. Both series have a positive autoregressive component. However, only CEEI has significant ARCH effects. The parameter $g$, which represents the average difference in volatility between the two states is the same for both series, at 5.19 times.

Table 3 presents the univariate results from running a switching ARCH model on the logreturns of our index series. We use a model with one lag for the autoregressive part and ARCH parts and two volatility states (hence, we use a $\operatorname{AR}(1)-\operatorname{SWARCH}(2,1)$ model). Time period: 03.01.2007 to 09.02.2010. Indices: as shown in the table. Standard errors in parentheses. Statistical significance at the 1,5 and 10 percent levels is denoted by ${ }^{* * *}{ }^{* *}$, and ${ }^{*}$, respectively. 
Table 3 Univariate index results, SWARCH model

\begin{tabular}{lcc}
\hline Markets & CEEI & CEEI2 \\
\hline $\mathrm{C}$ & 0.0130 & 0.0554 \\
& $(0.0378)$ & $(0.0430)$ \\
AR(1) & $0.1218^{* * * *}$ & $0.0828^{* *}$ \\
& $(0.0379)$ & $(0.0376)$ \\
$\mathrm{K}$ & $0.7230^{* * * *}$ & $1.0706^{* * *}$ \\
& $(0.1287)$ & $(0.1692)$ \\
ARCH(1) & $0.0796^{*}$ & 0.0229 \\
& $(0.0435)$ & $(0.0467)$ \\
$\mathrm{g}$ & $5.1893^{* * * *}$ & $5.1852^{* * *}$ \\
& $(0.8192)$ & $(0.8699)$ \\
DoF & $7.5722^{* * * *}$ & $10.0821^{* * *}$ \\
& $(2.3573)$ & $(3.5362)$ \\
Log Lik & 1346.5766 & 1393.2723 \\
\hline
\end{tabular}

In Figure 1, we show the results for the smoothed probabilities of the high-volatility state for the markets in our sample for our CEEI indices. We observe that WE is in the high volatility state for a shorter period of time than CEE during the peaks of the financial crisis, especially around the collapse of Lehman brothers in September 2008. Adding Turkey in CEEI2 reduces the volatility of the index, most notably in the period after May 2009. This figure shows unequivocally that CEE markets enter periods of instability in response to increases in uncertainty on WE markets.

Figure 1 presents the smoothed probabilities that the stock index in question (Stoxx600, CEEI or CEEI2) is in high volatility state (this probability is denoted by "Pr. H State"). For interpretation of the figure, see Figure 1 or the text. Stoxx600 is included for the sake of comparison. Time period: 03.01.2007 to 09.02.2010. Indices: as shown in the figure.
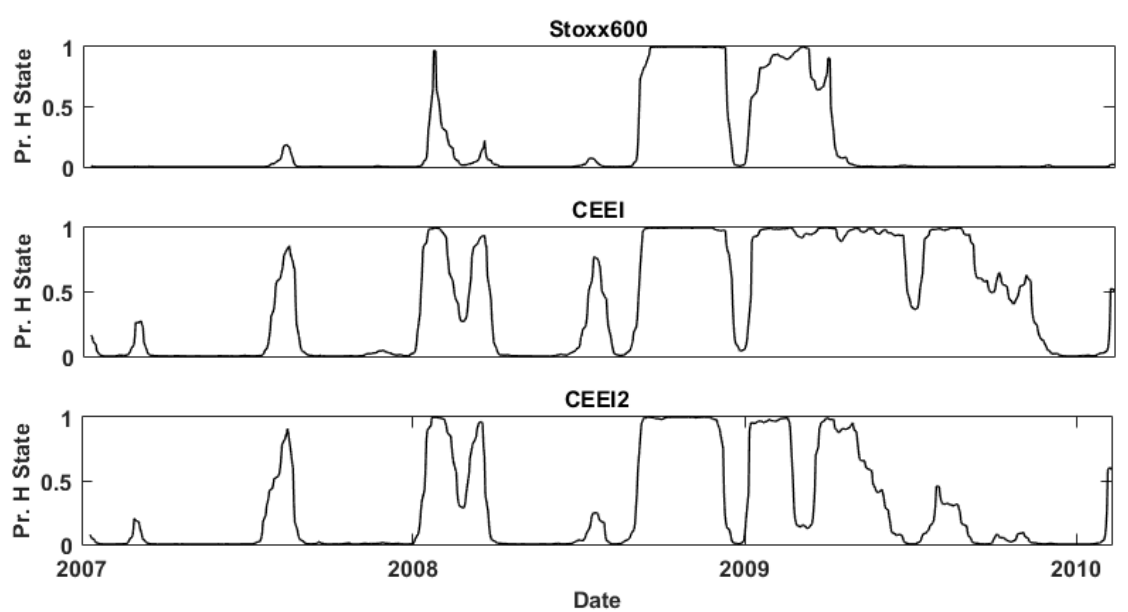

Fig. 1 Univariate case: smoothed probabilities, high volatility state 


\subsection{Bivariate Results}

Figures 2 and 3 present the bivariate smoothed probabilities. The top subplot depicts the probability that both markets are jointly in a state of low volatility. In the second subplot, the WE market is in the calm state and the respective CEE index is in a state of high volatility. The lower two subplots present he cases where WE is in turmoil and CEE is in the calm and highly volatile state, respectively. We observe that in both figures, in State 4, the dynamics matches the results for the univariate smoothed probabilities of WE in Figure 1. This means that when $\mathrm{WE}$ is in a turmoil, both versions of the CEE index are in a state of high volatility, once again supporting our assumption that a crisis in WE markets starts before a crisis on CEE markets.

Supporting the last point, on both graphs, we notice a small peak around Lehman Brothers' bankruptcy in September 2008 for State 3. This indicates that WE enters the high volatility state first, and a few days later it is joined by the transition region (evident by the huge and prolonged peak in State 4 where both markets are in high volatility state). Even if this is not a direct proof that the crisis in the latter region was caused by the turmoil in the Western markets, we at least find evidence that the crisis in CEE was preceded by the crisis in WE (hence suggesting Granger causality).

Figure 2 presents the smoothed probabilities that the bivariate couple Stoxx600 - CEEI is in any of the four states described in Section 4.3. The top subplot depicts the probability that both markets are jointly in a state of low volatility. In the second subplot, the WE market is in the calm state and the respective CEE index is in a state of high volatility. The lower two subplots present the cases where WE is in turmoil and CEE is in the calm and highly volatile state, respectively. We assume that the dependence structure changes only when WE shifts from low to high volatility state (for example, from states 1 or 2 to states 3 or 4; see Section3.3.). Time period: 03.01.2007 to 09.02.2010.
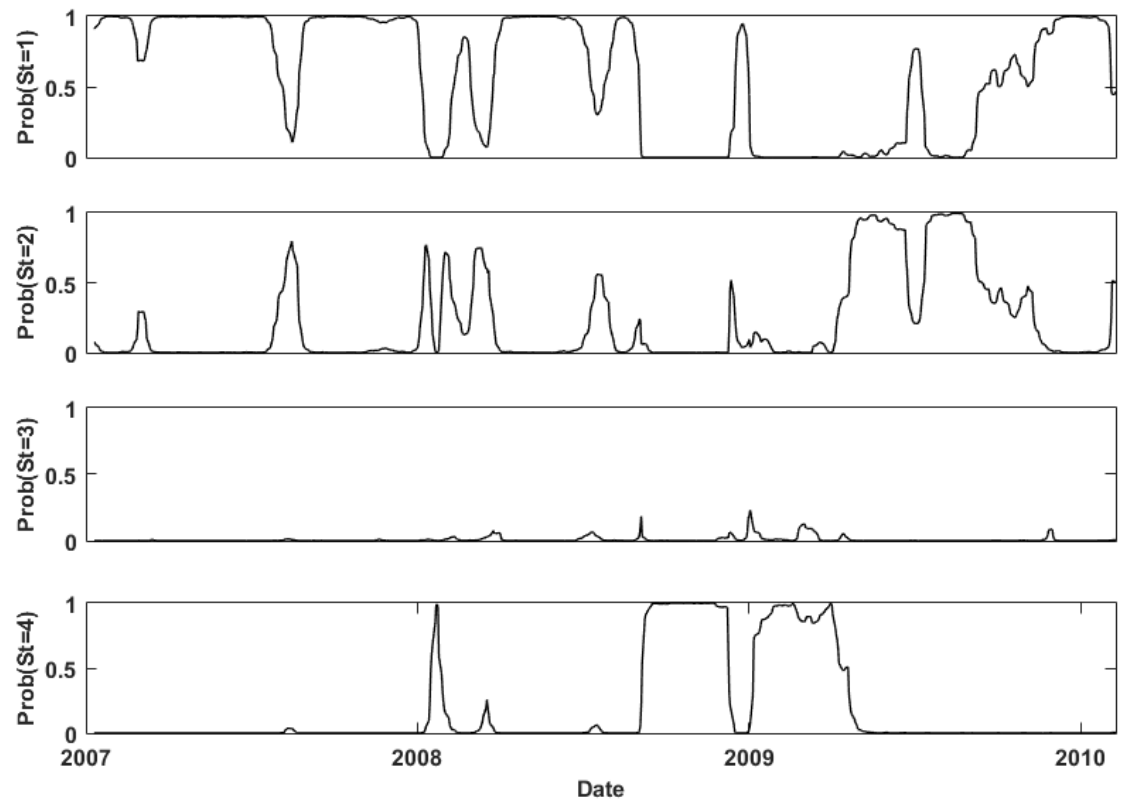

Fig. 2 Bivariate case: WE - CEEI 
Comparing Figures 2 and 3, we notice that the probability of both WE and CEE regions to be in low volatility state (State 1) is much higher for CEEI2 than for CEEI after the first quarter of 2009. As Turkey is the bigger of both countries added in the broader index, our results suggest that through its diversified economy, this country improves the stability and resilience of the region to external shocks.

Figure 3 presents the smoothed probabilities that the bivariate couple Stoxx600 CEEI2 is in any of the four states described in Section 4.3. The top subplot depicts the probability that both markets are jointly in a state of low volatility. In the second subplot, the WE market is in the calm state and the respective CEE index is in a state of high volatility. The lower two subplots present the cases where WE is in turmoil and CEE is in the calm and highly volatile state, respectively. We assume that the dependence structure changes only when WE shifts from low to high volatility state (for example, from states 1 or 2 to states 3 or 4; see Section 3.3.). Time period: 03.01.2007 to 09.02.2010.
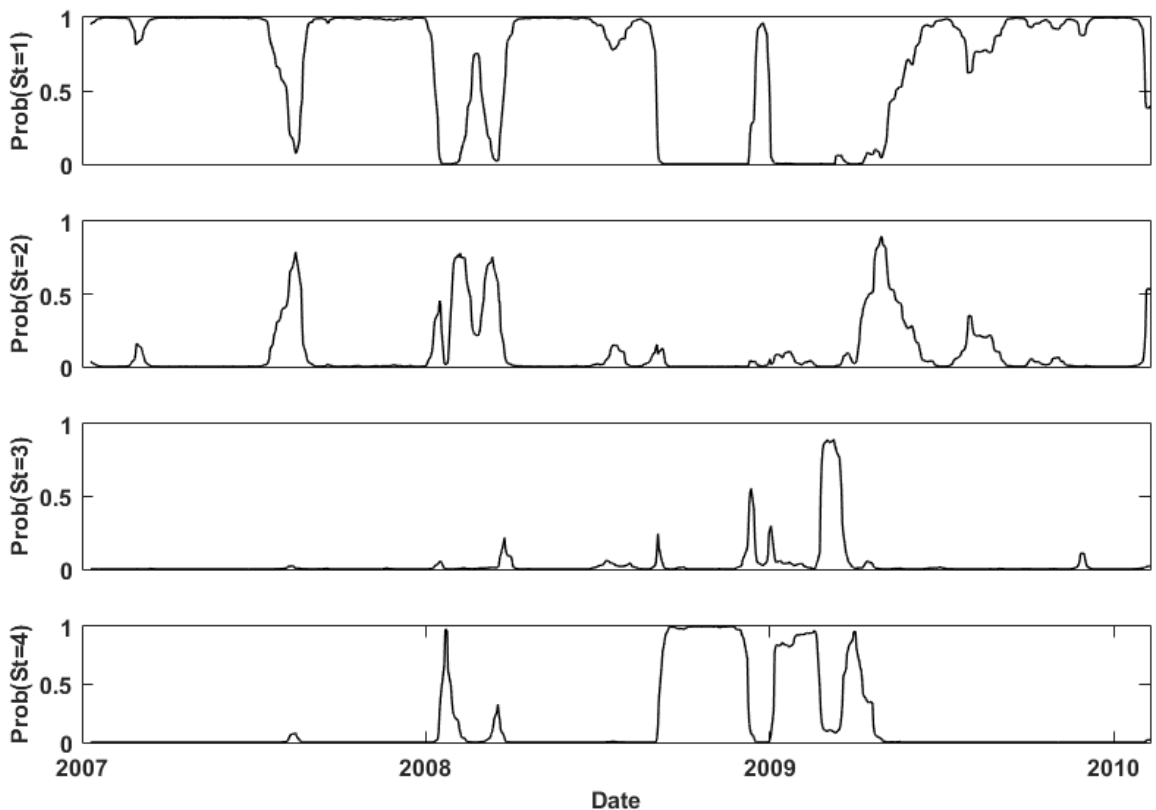

Fig. 3 Bivariate case: WE - CEEI2

Turning to the analysis of tail dependence between WE and CEE. The main hypothesis that we test is whether tail dependence increases during turmoils. To this end, we turn our attention to the tail dependence estimates as represented by the coefficients of the switching copula. Table 4 summarizes our estimates of upper and lower tail dependence, $\tau^{U}$ and $\tau^{L}$. We notice that all tail dependence coefficients are statistically significant at the $1 \%$ level. When we compare upper and lower tail dependence in low and high volatility states, we observe that the dependence structure becomes more symmetric in crisis times (that is, during high volatility periods). The asymmetry in tranquil times is more noticeable for the wider index, where we witness lower upper and higher lower tail dependence, compared to the respective estimates for CEEI. We 
also notice that for both indices the lower tail dependence increases substantially in high volatility times ( 37.5 and 24.6 percent for CEEI and CEEI2, respectively).

Table 4 presents the tail dependence estimates of a switching symmetrized Joe-Clayton (SJC) copula between Western Europe (WE) and the two CEEI indices, as well as their relative change (in \%) when $\mathrm{WE}$ is in low and high volatility states, respectively. The bottom two rows present the ratios between lower and upper tail dependence in the low and high volatility states. Time period: 03.01.2007 to 09.02.2010. Indices: as shown in the table. Standard errors for the individual tail dependence coefficients in parentheses. Statistical significance at the 1,5 and 10 percent levels is denoted by $* * *, * *$, and *, respectively.

Table 4 Tail dependence results: CEEI and CEEI2

\begin{tabular}{lcc}
\hline Markets & CEEI & CEEI2 \\
\hline$\tau^{U}($ WE low $)$ & $0.4023^{* * *}$ & $0.3784^{* * * *}$ \\
& $(0.0593)$ & $(0.0675)$ \\
$\tau^{U}($ WE high $)$ & $0.6307^{* * * *}$ & $0.6503^{* * *}$ \\
& $(0.0284)$ & $(0.0266)$ \\
$\tau^{L}($ WE low $)$ & $0.4892^{* * *}$ & $0.5436^{* * *}$ \\
& $(0.0447)$ & $(0.0415)$ \\
$\tau^{L}($ WE high $)$ & $0.6724^{* * *}$ & $0.6773^{* * *}$ \\
& $(0.0228)$ & $(0.0235)$ \\
Log Lik & 3872.1934 & 3889.3090 \\
\hline
\end{tabular}

These results suggest that a shift in dependence between CEE and WE did occur when Western markets entered high volatility states. However, although we observe an asymmetric dependence structure between the regions when WE markets are in low-volatility state, we do not confirm its existence during high-volatility periods. Nevertheless, lower tail dependence does increase during a turmoil, confirming our expectations. The overall dependence between the regions is relatively symmetric in such periods, but at a higher level. Hence, we find support for the existence of financial contagion (as defined by Forbes \& Rigobon 2002) at the regional level.

\section{CONCLUSION}

We introduce an innovative approach to analyze the interactions between the financial markets of WE and CEE during the Great Recession. This new approach allows us to investigate changes in both the level and the symmetry of interdependence.

Our results suggest that dependence, in particular lower tail dependence, has increased during the peaks of the global financial crisis. In general, the two CEE indices that we introduce follow the dynamics of their bigger constituents, Poland and Turkey, and the inclusion of the latter country reduces the duration of the crisis periods in the region. Surprisingly, we find that the tail dependence on the WE region - CEE region level is symmetric during periods of high volatility. However, the level of tail dependence (both upper and lower) of around 0.60 in high volatility states seems exceptionally high and further analysis at the country level is warranted to reveal the interactions between individual markets and the WE and whether there is evidence for heterogeneity within the region. 
The outcomes of our study have important implications also for the ongoing economic and political integration within the EU and especially of Turkey with the EU. We find evidence that EU candidate countries could reduce the uncertainty and hence the vulnerability of CEE stock markets. This could be an important topic for further research.

\section{REFERENCES}

Ang, A., \& Bekaert, G. (2002). International Asset Allocation with Regime Shifts. Review of Financial Studies, 15(4), 1137-1187. https://doi.org/10.1093/rfs/15.4.1137

Baele, L., Bekaert, G., \& Schäfer, L. (2015). An Anatomy of Central and Eastern European Equity Markets. Columbia Business School Research Paper No. 15-71.

Baruník, J., \& Vácha, L. (2013). Contagion among Central and Eastern European Stock Markets during the Financial Crisis. Czech Journal of Economics and Finance (Finance a uver), 63(5), 443-453.

Beck, K., \& Stanek, P. (2019). Globalization or Regionalization of Stock Markets? the Case of Central and Eastern European Countries. Eastern European Economics, 57(4), 317-330. https://doi.org/10.1080/00128775.2019. 1610895

Bertero, E., \& Mayer, C. (1990). Structure and performance: Global interdependence of stock markets around the crash of October 1987. European Economic Review 34(6), 1155-1180. https://doi.org/10.1016/00142921(90)90073-8

Boyer, B., Gibson, M., \& Loretan, M. (1999). Pitfalls in tests for changes in correlations. IFS Discussion Paper No. 597R, Federal Reserve Board.

Csiki, M., \& Kiss, G. (2018). Capital Market Contagion in the Stock Markets of Visegrád Countries Based on the Heckman Selection Model. Financial and Economic Review, 17(4), 23-52. http://doi.org/10.25201/FER.17.4.2352

Dabrowski, M. (2009). The global financial crisis: Lessons for European Integration. CASE Network Studies \& Analyses, No. 384, Center for Social and Economic Research (CASE), Warsaw.

Egert, B., \& Kočenda, E. (2011). Time-varying synchronization of European stock markets. Empirical Economics, 40(2), 393-407. https://doi.org/10.1007/s00181-010-0341-3

Friedrich, C., Schnabel, I., \& Zettelmeyer, J. (2013). Financial Integration and Growth Why is Emerging Europe Different. Journal of International Economics, 89(2), 522-538. https://doi.org/10.1016/j.jinteco.2012.07.003

Forbes, K., \& Rigobon, R. (2002). No Contagion, Only Interdependence: Measuring Stock Market Comovements. Journal of Finance, 57(5), 2223-2261. https://doi.org/10.1111/0022-1082.00494

Gardó, S., \& Martin, R. (2010). The Impact of The Global Economic and Financial Crisis on Central, Eastern and South-Eastern Europe: A Stock-Taking Exercise. ECB Occasional Paper Series No. 114 / June 2010. European Central Bank, Frankfurt.

Grabowski, W. (2019). Givers or Recipients? Co-Movements between Stock Markets of CEE-3 and Developed Countries. Sustainability, 11(22), 1-24. https://doi.org/10.3390/su11226495

Hamilton, J., \& Susmel, R. (1994). Autoregressive conditional heteroskedasticity and changes in regime. Journal of Econometrics, 64(1-2), 307-333. https://doi.org/10.1016/0304-4076(94)90067-1

Haselmann, R., Pistor, K., \& Vig, V. (2009). How Law Affects Lending. Review of Financial Studies, 23(2), 549580. https://doi.org/10.1093/rfs/hhp073

Horváth, R., Lyócsa, S., \& Baumöhl, B. (2018). Stock market contagion in Central and Eastern Europe: unexpected volatility and extreme co-exceedance. The European Journal of Finance, 24(5), 391-412. https://doi.org/10.1080/ 1351847X.2017.1307773

Horváth, R., \& Petrovski, D. (2013). International stock market integration: Central and South Eastern Europe compared. Economic Systems, 37(1), 81-91. https://doi.org/10.1016/j.ecosys.2012.07.004

King, M., \& Wadhwani, S. (1990). Transmission of Volatility between Stock Markets. Review of Financial Studies, 3(1), 5-33.

Longin, F., \& Solnik, B. (2001). Extreme correlations of international equity markets. Journal of Finance, 56, 649-676. https://doi.org/10.1111/0022-1082.00340

Moagăr-Poladian, S., Clichici, D., \& Stanciu, C.-V. (2019). The Comovement of Exchange Rates and Stock Markets in Central and Eastern Europe. Sustainability, 11(14), 1-22. http://dx.doi.org/10.3390/su11143985

Mohti. W, Dionísio. A, Ferreira, P., \& Vieira, I. (2019). Contagion of the Subprime Financial Crisis on Frontier Stock Markets: A Copula Analysis. Economies, 7(15), 1-14. https://doi.org/10.3390/economies7010015

Nelsen, R. (2006), An Introduction to Copulas, New York, 2nd edn, Springer Verlag.

Niţoi, M., \& Pochea, M. (2019). What drives European Union stock market co-movements?. Journal of International Money and Finance, 97, 57-69. https://doi.org/10.1016/j.jimonfin.2019.06.004 
Patton, A. (2006). Modelling Asymmetric Exchange Rate Dependence. International Economic Review, 47(2), 527-556. https://doi.org/10.1111/j.1468-2354.2006.00387.x

Rachev, S., \& Mittnik, S. (2000). Stable Paretian Models in Finance. John Wiley \& Sons, Ltd., Chichester.

Ramchard, L., \& Susmel, R. (1998). Volatility and Cross Correlation Across Major Stock Markets. Journal of Empirical Finance, 5, 397-416. https://doi.org/10.1016/S0927-5398(98)00003-6

Reboredo, J., Tiwari, A., \& Albulescu, C. (2015). An analysis of dependence between Central and Eastern European stock markets. Economic Systems, 39(3), 474-490. https://doi.org/10.1016/j.ecosys.2015.01.002

Rodriguez, J. (2007). Measuring financial contagion: A Copula approach. Journal of Empirical Finance, 14(3), 401-423. https://doi.org/10.1016/j.jempfin.2006.07.002

Sklar, A. (1959). Fonctions de repartition a' $\mathrm{n}$ dimensions et leurs marges [Functions of n-dimensional distribution and their margins]. Publications de l'Institut de Statistique de L'Universit de Paris, 8, 229-231.

Tilfani, O., Ferreira, P., \& El Boukfaoui, M. (2020). Revisiting stock market integration in Central and Eastern European stock markets with a dynamic analysis. Post-Communist Economies, 32(5), $643-674$. https://doi.org/10.1080/14631377.2019.1678099

\section{NOVA METODOLOGIJA ZA PROUČAVANJE TRANSMISIJE IZMEĐU ZAPADNE I SREDNJEISTOČNE EVROPE: PROMENLJIVE VEZE}

Ovaj rad prihvata i proširuje modele promenljivih veza kako bi istražio da li se dogodila finansijska transmisija između zapadnih berzi i njihovih parnjaka u Centralnoj i Istočnoj Evropi tokom Globalne finansijske krize. Naša metodologija se fokusira na krajnju zavisnost kao direktnu meru ko-zavisnosti u vremenu krize i primenjujemo je na dva indeksa po meri koja pokrivaju najveće centralno- $i$ istočnoevropske berze. Nalazimo uopšteno povećanje u zavisnosti između Zapadne Evrope i tranzicione regije za vreme Velike recesije. Međutim, dodavanje turske berze u naše CEE regionalne indekse smanjuje trajanje usticaja krize. Ovi rezultati sugerišu da tranzicione ekonomije ostaju vredni izvori diverzifikacije u kriznm periodima.

Ključne reči: Transmisija, Međunarodna finansijska tržišta, Finansijska integracija 